\section{ACCELEROMETRY UNDERESTIMATES ENERGY EXPENDITURE IN CIRCUIT-BASED RESISTANCE TRAINING}

\author{
ACELEROMETRIA SUBESTIMA GASTO ENERGÉTICO EM CIRCUITOS DE TREINAMENTO DE FORÇA \\ ACELEROMETRÍA SUBESTIMA GASTO ENERGÉTICO EN CIRCUITOS DE ENTRENAMIENTO DE FUERZA
}

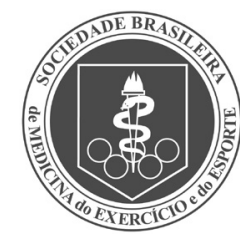

Original Article

ArtIGO ORIGINAL Artículo Original

\section{Ana Belén Peinado' (1D) (Physical Education Professional) Eliane Aparecida Castro ${ }^{1,2}$ (ID (Physical Education Professional) Augusto García Zapico 3,4 (ID (Physical Education Professional) Pedro Jose Benito' (iD) (Physical Education Professional)}

1. Universidad Politécnica de Madrid, Faculty of Physical Activity and Sport Sciences, LFE Research Group, Department of Health and Human Performance,

Madrid, Spain.

2. Universidad Católica de la Santísima Concepción, Faculty of Education, Department of Sports Sciences and Physical Conditioning, Concepción, Chile. 3. Universidad Complutense de Madrid, Faculty of Education, Madrid, Spain.

4. Universidad Politécnica de Madrid, ImFINE Research Group, Madrid, Spain.

\section{Correspondence:}

Eliane Aparecida Castro.

Universidad Católica de la Santísima Concepción, Facultad de Educación. Departamento de Ciencias del Deporte y Acondicionamiento Físico. Av. Alonso de Ribera, 2850, Concepción, Bío Bío, Chile. Código Postal 4081393.

elianeaparecidacastro@gmail.com

\begin{abstract}
Introduction: Accelerometry is a very accurate method for determining energy expenditure (EE) in endurance training. However, further studies are needed to prove its accuracy in resistance training. Objective: To compare the EE obtained by accelerometry and indirect calorimetry in three different circuit resistance training circuits. Methods: Six overweight volunteers performed three sets in three resistance training circuits: machine circuit (MC), free-weight circuit (FWC) and resistance + aerobic circuit (RAC). EE was measured by indirect calorimetry using an Oxycon Mobile ${ }^{\oplus}$ and by the accelerometers SenseWear ${ }^{\bullet}$ Armband Pro2 2 and ActiTrainer ${ }^{\circledR}$. Results: ActiTrainer ${ }^{\oplus}$ and SenseWear ${ }^{\circledR}$ underestimated EE in all circuits when compared to indirect calorimetry $(p<0.05)$. The difference was greater in the FWC: $44.4 \%$ METs and $81.4 \%$ Kcal for ActiTrainer ${ }^{\oplus}$ and $32.3 \%$ METs and $24.9 \%$ Kcal for SenseWear ${ }^{\oplus}$ compared to indirect calorimetry. Conclusion: Both ActiTrainer ${ }^{\oplus}$ and SenseWear ${ }^{\oplus}$ underestimated EE when compared to indirect calorimetry in three different resistance training circuits. Level of evidence II; Diagnostic studies - Investigating a diagnostic test.
\end{abstract}

Keywords: Circuit-based exercise; Energy expenditure; Overweight.

\section{RESUMO}

Introdução: A acelerometria é um método muito preciso para determinar o gasto energético (GE) no treinamento de resistência. No entanto, são necessários mais estudos para provar sua precisão no treinamento de força. Objetivos: Comparar o GE obtido por acelerometria e calorimetria indireta em três diferentes circuitos de treinamento de força. Métodos: Seis voluntários com sobrepeso executaram três voltas em três circuitos de treinamento de força: circuito com máquinas (CM), circuito com pesos livres (CPL) e circuito de força + aeróbico (CFA). O GE foi medido por calorimetria indireta através do Oxycon Mobile ${ }^{\oplus}$ e pelos acelerômetros ActiTrainer ${ }^{\circledR}$ e SenseWear ${ }^{\circledR}$ Armband Pro2. Resultados: O ActiTrainer ${ }^{\oplus}$ e o SenseWear ${ }^{\oplus}$ subestimaram o GE em todos os circuitos em comparação com a calorimetria indireta ( $p<0,05)$. A diferença foi maior no CPL: 44,4\% de MET e 81,4\% Kcal para ActiTrainer ${ }^{\oplus}$ e 32,3\% deMET e 24,9\% Kcal para SenseWear ${ }^{\oplus}$ comparados com calorimetria indireta. Conclusão: Ambos os acelerômetros, ActiTrainer ${ }^{\oplus}$ e SenseWear ${ }^{\oplus}$, subestimaram o GE quando comparados com a calorimetria indireta em três circuitos diferentes de treinamento de força. Nível de evidência ll; Estudos diagnósticos -Investigação de um exame para diagnóstico.

Descritores: Exercícios em circuitos; Gasto energético; Sobrepeso.

\section{RESUMEN}

Introducción: La acelerometría es un método muy preciso para determinar el gasto de energía (GE) en el entrenamiento de resistencia. Sin embargo, son necesarios más estudios para probar su precisión en el entrenamiento de fuerza. Objetivos: Comparar el GE obtenido por acelerometría y calorimetría indirecta en tres diferentes circuitos de entrenamiento de fuerza. Métodos: Seis voluntarios con sobrepeso ejecutaron tres vueltas en tres circuitos de entrenamiento de fuerza: circuito con máquinas (CM), circuito con pesos libres (CPL) y circuito de fuerza + aeróbico (CFA). El GE fue medido por calorimetría indirecta a través de Oxycon ${ }^{\circledR}$ Mobile y por los acelerómetros ActiTrainer ${ }^{\circledast}$ y SenseWear ${ }^{\oplus}$ Armband Pro2. Resultados: ActiTrainer ${ }^{\oplus}$ y SenseWear ${ }^{\oplus}$ subestimaron el GE en todos los circuitos en comparación con la calorimetría indirecta $(p<0,05)$. La diferencia fue mayor en el CPL: 44,4\% de MET y 81,4\% Kcal para ActiTrainer ${ }^{\oplus}$ y $32,3 \%$ de MET y 24,9\% Kcal para SenseWear ${ }^{\oplus}$ comparados con calorimetría indirecta. Conclusión: Ambos acelerómetros, ActiTrainer ${ }^{\oplus}$ y SenseWear ${ }^{\varpi}$, subestimaron el GE cuando comparados con la calorimetría indirecta en tres circuitos diferentes de entrenamiento de fuerza. Nivel de evidencia Il; Estudios diagnósticos - Investigación de un examen para diagnóstico.

Descriptores: Ejercicio en circuitos; Gasto de energía; Sobrepeso. 


\section{INTRODUCTION}

Individuals who are regularly active have significantly better health than sedentary subjects due to the relationships between physical activity (PA) and several chronic diseases such as obesity and cardiovascular diseases. ${ }^{1}$ The accurate and specified measurement of PA is therefore a crucial prerequisite to investigate its association with health and disease, although this measurement has been characterized by difficult and questionable accuracy assessment. ${ }^{2}$

A variety of methods to measure PA and energy expenditure (EE) are available, however some important limitations remain. These methods can be classified into five categories: subjective reports and observations (questionnaires and activity diaries), physiological markers (heart rate $(\mathrm{HR})$, body temperature and ventilation), double-labelled water (DLW), direct and indirect calorimetry, and portable motion sensors (accelerometers and pedometers). ${ }^{3}$ DLW and calorimetry are considered the best and most accurate tools for measuring $\mathrm{EE}_{1}{ }^{4}$ but they are expensive and difficult to access. Both direct and indirect calorimetry are very accurate methods to determine EE with an error lower than 1\%. ${ }^{5}$ However, indirect calorimeters are relatively complex and require trained personnel for their correct use. On the other hand, motion sensors such as accelerometers are easier to use and do not require as much experience.

Accelerometers measure body movements in terms of accelerations and decelerations in one or more directions of motion, which are summarized to reflect intensity and frequency of human beings. ${ }^{6}$ Several studies have validated accelerometers as PA and EE measurement tools. ${ }^{6,7}$ Nonetheless, in some activities such as resistance exercise, accelerometers may appear to be inaccurate when measuring EE. 2,8,9

Therefore the aim of this article was to investigate the applicability and accuracy of two common accelerometers, comparing the outcomes in terms of EE with indirect calorimetry in three different circuits of resistance training (CRT).

\section{METHODS}

Six overweight volunteers (body mass index $27.02 \pm 2.75 \mathrm{~kg} / \mathrm{m}^{2}$; age $32.5 \pm 10.8$ years), moderately actives (3-5 h/wk of exercise with at least one year of experience in strength training assessed through the short version of the International Physical Activity Questionnaire) participated in this study. Smokers or individuals reporting a history of diabetes, cardiovascular disease or metabolic disorders were excluded. All of the participants sign a written informed consent to join the study, which was approved by the Human Research Review Committee of the University Hospital La Paz (PI-643).

Each volunteer visited the laboratories in seven occasions: the first four visits involved the calculation of 15 maximum repetitions (15 RM), while the final three visits were to perform the full CRT protocols. To calculate the $15 \mathrm{RM}$, each exercise was tested twice on different days during the previous two weeks before the CRT protocols. A maximum of two attempts were performed in the same day. The test started after a five minutes cardiovascular cycle ergometer warm-up and consisted of three sets of 15 repetitions at 50\%,70\% and 90\% of the estimated 15 RM, with a two minutes recovery between them to approach the maximum load. Following these three sets, subjects rested for five minutes and then a final set of 15 repetitions was carried out at 100\% of the estimated 15 RM. ${ }^{10}$

Prior to the onset of each CRT protocol, the three devices (Oxycon Mobile ${ }^{\circledast}$, SenseWear ${ }^{\circledast}$ Armband Pro2 and ActiTrainer ${ }^{\circledR}$ ) were placed on the volunteer to measure EE.

\section{Assessments}

Indirect calorimetry was assessed by the gas analyser and portable metabolic system Oxycon Mobile ${ }^{\circledR}$ (Erich Jaeger, Viasys Healthcare, Germany)
$(\mathrm{OX})$, which has been validated to measure oxygen consumption $\left(\mathrm{VO}_{2}\right)^{11,12}$ The OX was calibrated prior to each session and $\mathrm{VO}_{2}$ was recorded in 10 seconds epochs. For comparison, the $\mathrm{VO}_{2}$ was converted into METs and $\mathrm{Kcal}\left(\mathrm{VO}_{2} / 3.5 \mathrm{ml} \cdot \mathrm{kg}^{-1} \cdot \mathrm{min}^{-1}\right)$.

Accelerometry was measured by the SenseWear ${ }^{\circledR}$ Armband Pro2 (Bodymedia Inc. Pittsburgh, PA - version 5.0) (SWA) and the ActiTrainer ${ }^{\oplus}$ (Actigraph, Fort Walton Beach, FL, USA) (ACT). SWA was placed on the upper dominant arm (over the triceps muscle) and ACT was worn on a belt at the midaxillary line of the right hip as per manufacturer's orientations. SWA, in comparison with DLW, has shown remarkable accuracy in assessing EE at rest and during low moderate intensity PA in adults, as evidenced by an intraclass correlation of $0.81(p<0.01){ }^{13}$ Furthermore, Fruin et al. ${ }^{14}$ reported no statistical differences between SWA and indirect calorimetry measurements in rest and ergometer tests. Related to EE measurements by ACT some studies have shown conflicting results: Rothney et al. ${ }^{15}$ reported that the ACT was able to predict time spent in moderate and vigorous activities with $<2 \%$ error; while Crouter et al. ${ }^{16}$ asserted that the various methods available in literature for the ACT failed to predict EE accurately when applied to a wide range of intensities. Nonetheless, in a related publication, Crouter et al. ${ }^{17}$ developed a more accurate estimation formula, for which EE was within 0.75 METs away from actual values as measured by indirect calorimetry. For SWA, second-by-second values were reported as either Kcal or METs and data were downloaded into the INNERVIEW software. Regarding ACT, built in algorithms were applied to determine: the amount of EE in $\mathrm{Kcal}_{1}^{18}$ corresponding METs ${ }^{17}$ and steps taken by the participant. In addition, a HR monitor (Polar ${ }^{\circledR}$ Electro, Kempele, Finland) was used to record $\mathrm{HR}$ data throughout the entire workout.

\section{Circuits resistance training}

Three different CRT were used in this study: machines circuit (MC), free-weights circuit (FWC) and resistance + aerobic circuit (RAC). The MC was composed of eight exercises: 1) sitting bench press, 2) leg extension, 3) lat pull down, 4) inclined leg press, 5) shoulder press in machine, 6) leg curl, 7) biceps curl machine, 8) cable push downs. The FWC of: 1) dumbbells shoulder press, 2) barbell squats, 3) barbell row, 4) barbell side split squat, 5) bench press, 6) barbell split squat, 7) barbell biceps curl and 8) lying triceps extension. Lastly, the RAC was composed of: 1) barbell squats, 2) running, 3) seated cable row, 4) running, 5) barbell split squat, 6) running, 7) barbell biceps curl and 8) running.

The protocol began with the volunteer performing a warm-up which involved 5 min running on a treadmill at $50 \%$ of $H R$ reserve ${ }^{19}(H R R)$ followed by 1 min rest and a first lap of the CRT at 20\% of 15 RM. A 1 min recovery was provided before the volunteer performed the training protocol. Machine exercises were performed on Pannata ${ }^{\circledR}$ machines, Italy. Each resistance exercise involved 15 repetitions at 70\% of 15 RM following a 2:1 second cadence for the concentric and eccentric phases, respectively (45 seconds per exercise). The cadence was controlled by sounds recorded on a compact disc. Running during the RAC was performed at 70\% of the HRR. Between exercises, 15 seconds were provided to allow subjects to change from one station to the next. The total duration of one lap was 7 minutes and 45 seconds. Because each volunteer had to perform three laps, the total duration was 23 min and $15 \mathrm{~s}$, and the entire session (including warm-up) took $64 \mathrm{~min}$.

\section{Statistical analysis}

All values were reported as mean \pm standard deviation (SD). The differences between OX vs. SWA, OX vs. ACT and SWA vs. ACT measurements in METs and Kcal were evaluated with a paired t-Student test. Bland-Altman bias plots were created to assess the agreement between OX-SWA, OX-ACT and SWA-ACT measurements and estimations of EE. Two-way ANOVA with repeated measures ( 3 circuits $\times 3$ devices) was used to assess differences in the calculated variables (Kcal and METs). A one-way ANOVA was used 
to compare the delta differences of the average between devices in each circuit. Multiple comparisons were made with the Bonferroni post hoc test. Comparisons of the differences between devices were converted to percentages (\%) by the following equation (OX value - SWA value)*100 / OX value). SPSS version 20.0 for Windows was used (SPSS Inc., Chicago, IL, USA). The significance level was set at $a<0.05$.

\section{RESULTS}

Participants' physical characteristics and CRT responses are shown descriptively in Table 1. $\mathrm{VO}_{2 \text { peak, }}, \mathrm{HR}$ and $\mathrm{EE}$ are presented as the average of the whole CRT (i.e. 3 laps) in all tables.

In general, ACT presented significant underestimation in EE in all CRT when compared with OX, mainly in the FWC: $44.4 \%$ in METs $(p<0.05)$ and $81.4 \%$ in Kcal $(p<0.05)$ as shown in Table 2. The same was true for the MC: $36.4 \%$ in METs $(p<0.05)$ and $77.6 \%$ in Kcal $(p<0.05)$. In the RAC, ACT presented its closest value compared to OX although the differences were still significant: $27.1 \%$ in METs ( $p=0.007)$ and $46.6 \%$ in Kcal ( $p=0.003)$.

Compared with SWA, the ACT also showed significant underestimation in EE measurement. The biggest difference was found in the FWC in Kcal: 75.2\% ( $p<0.05)$, although no differences were found in METs ( $p>0.05)$.

As observed in Table 2, SWA also underestimated significantly of EE in METs compared with OX in the MC $(17.4 \%, p=0.007)$ although no differences were found in Kcal $(p=0.264)$. In the FWC, SWA presented significant underestimation in METs $(32.3 \%, p<0.001)$ and Kcal $(24.9 \%, p=0.015)$. In the RAC, SWA showed a significant underestimation only in METs (28.7\%, $p=0.004)$. No significant differences were found in Kcal ( $p=0.612)$.

Finally, Bland-Altman plots revealed absolute differences between devices. While OX vs. SWA bias values were 1.01, s=0.5 METs and 52.3, s=65.3 Kcal, OX vs. ACT were 1.35, s=0.4 METs and 231.2, s=76.9 Kcal (Figure 1). In addition, SWA vs. ACT bias values were $0.33, s=0.51$ METs and 178.9, $s=62.9 \mathrm{Kcal}$.

The differences between devices in each circuit are shown in Table 3. In the RAC, the differences between OX vs. SWA were significantly higher than the $\mathrm{MC}$ value $(1.33, \mathrm{~s}=0.43 \mathrm{vs} .0 .59, \mathrm{~s}=0.9 \mathrm{MET}$, respectively) ( $p=0.021)$. No differences in Kcal were found between the cited circuits ( $p>0.05)$. On the other hand, the difference between OX vs. ACT was the highest in the FWC, followed by MC and RAC as shown in Table 3.

Table 1. Volunteers characteristics.

\begin{tabular}{c|c}
\hline Variables & Mean \pm SD \\
\hline Weight $(\mathrm{kg})$ & $81.1 \pm 13.1$ \\
\hline Height $(\mathrm{cm})$ & $173.0 \pm 10.3$ \\
\hline BMI $\left(\mathrm{kg} / \mathrm{m}^{2}\right)$ & $27.02 \pm 2.75$ \\
\hline Body fat $(\%)$ & $22.4 \pm 9.3$ \\
\hline$H R($ beats $/ \mathrm{min})$ at MC & $116.7 \pm 18.1$ \\
\hline $\mathrm{FWC}$ & $127.8 \pm 6.9$ \\
\hline $\mathrm{RAC}$ & $128.8 \pm 13.4$ \\
\hline $\mathrm{VO}_{2 \text { peak }}(\mathrm{ml} / \mathrm{kg} / \mathrm{min})$ at MC & $11.8 \pm 0.7$ \\
\hline $\mathrm{FWC}$ & $12.7 \pm 0.6$ \\
\hline $\mathrm{RAC}$ & $16.0 \pm 2.4$ \\
\hline
\end{tabular}

BMI - body mass index; HR - heart rate; MC - machine circuit; FWC - free-weight circuit; RAC - resistance + aerobic circuit; $\mathrm{VO}_{2 \text { peak }}$ - peak oxygen consumption.

Table 2. Mean values of energy expenditure in each circuit and significant differences.

\begin{tabular}{|c|c|c|c|c|c|c|}
\hline & \multicolumn{2}{|c|}{ MC } & \multicolumn{2}{|c|}{ FWA } & \multicolumn{2}{|c|}{ RAC } \\
\hline & METs & Kcal & METs & Kcal & METs & Kcal \\
\hline OX & $3.38 \pm 0.23$ & $313 \pm 37$ & $3.65 \pm 0.16$ & $377 \pm 34$ & $4.56 \pm 0.7^{a, b}$ & $397 \pm 69^{a}$ \\
\hline SWA & $2.79 \pm 0.37^{1}$ & $268 \pm 59$ & $2.47 \pm 0.44^{1}$ & $283 \pm 71^{1}$ & $3.25 \pm 0.7^{1}$ & $337 \pm 98$ \\
\hline ACT & $2.15 \pm 0.2^{1,2}$ & $70 \pm 23^{1,2}$ & $2.03 \pm 0.11^{1}$ & $70 \pm 11^{1,2}$ & $3.32 \pm 0.21^{a, b, 1}$ & $212 \pm 60^{a, b, 1,2}$ \\
\hline
\end{tabular}
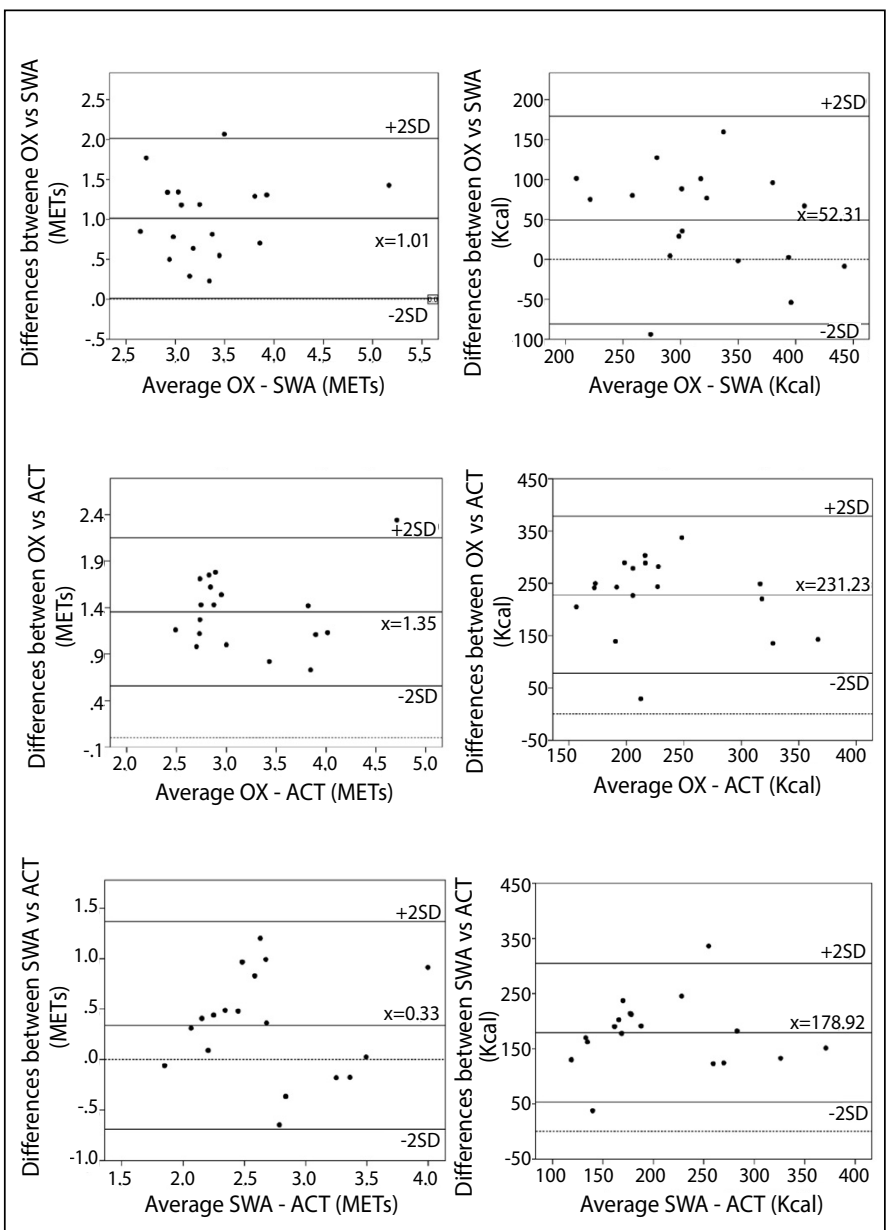

Figure 1. Bland-Altman plots at average of the difference between devices in METs and Kcal with grouped circuits.

Table 3. Delta differences of averages in each circuit in METs and Kcal.

\begin{tabular}{|c|c|c|c|c|}
\hline & MC & FWC & RAC & Grouped \\
\hline \multicolumn{5}{|c|}{ METs } \\
\hline OX vs. SWA & $0.59 \pm 0.9$ & $1.12 \pm 0.51$ & $1.33 \pm 0.43^{\mathrm{a}}$ & $1.01 \pm 0.5$ \\
\hline OX vs. ACT & $1.23 \pm 0.22$ & $1.56 \pm 0.25$ & $1.25 \pm 0.58$ & $1.35 \pm 0.4$ \\
\hline SWA vs. ACT & $0.63 \pm 0.36$ & $0.44 \pm 0.4$ & $-0.07 \pm 0.53^{a}$ & $0.33 \pm 0.51$ \\
\hline \multicolumn{5}{|c|}{ Kcal } \\
\hline OX vs. SWA & $45 \pm 37.6$ & $84.4 \pm 73.3$ & $27.4 \pm 75.3$ & $52.3 \pm 65.3$ \\
\hline OX vs. ACT & $242.7 \pm 27.8$ & $298.3 \pm 21.3$ & $152.6 \pm 77.1^{a, b}$ & $231.2 \pm 76.9$ \\
\hline SWA vs. ACT & $197.7 \pm 43.5$ & $213.8 \pm 62.5$ & $125.2 \pm 48.2^{b}$ & $178.9 \pm 62.9$ \\
\hline
\end{tabular}
compared with FWC. Values are mean $\pm S D(p<0.05)$.

\section{DISCUSSION}

The main finding of this study was that accelerometers ACT and SWA presented underestimation when measuring EE compared with indirect calorimetry in the three proposed CRT. Although many studies have shown the accuracy of these two accelerometers in many activities such as walking and daily PA, only a small number have shown the accuracy in proper exercise programs such as circuit training, weight lifting, etc. Thus, the results found in this study should be taken into consideration because determining the EE of resistance exercise sessions is important for individuals trying to improve body composition and lose weight.

In our results, we found that the ACT presented the highest underestimation, both in METs and Kcal. Primarily, this device technology is based on the ActiGraph accelerometer, commonly used in validation studies under laboratory and free-living conditions in various groups of 
adults and children. ${ }^{20-24}$ Recently, a study demonstrated that the ActiGraph and the ACT presented similar waist counts during resistance training. ${ }^{8}$

In relation to SWA, Benito et al. ${ }^{9}$ showed that this device underestimated EE during circuit weight training at three different intensities (50, 70 and $90 \%$ of $15 \mathrm{RM})$, where the underestimation increased as the intensity rose. Their results support our findings in the context that we have applied the same experimental CRT (MC) and shown that the SWA has underestimated EE when compared to indirect calorimetry (17.4\% in METs and $14.3 \%$ in Kcal). In addition, our results are in agreement with Drenowatz and Eisenmann ${ }^{2}$ who reported that SWA did not provide accurate estimates of EE at high intensity levels (65\%, 75\% and $85 \%$ of the $\mathrm{VO}_{2 \max }$ ). At high exercise intensities, Koehler et al. ${ }^{25}$ reported measuring errors while studying men running for 5 minutes above 6.3 $\mathrm{mph}(10 \mathrm{~km} / \mathrm{h})$. Although our study has utilized a low (<3 METs) to moderate (3.0-6.0 METs) intensity, we can also say that the underestimation increased as the intensity rose. This point can be explained by the fact that the FWC and the RAC presented higher EE outputs than the MC and higher underestimations, as shown previously.

On the other hand, a study reported that SWA was the best device to estimate the total EE at most speeds (up to $8 \mathrm{mph}$ ), with the exception of slow walking where it presented an overestimation of EE.? Moreover, even though some outputs obtained from SWA were significantly different in our study, this accelerometer had the closest agreement when compared with indirect calorimetry during the three proposed CRT.

Traditionally, the algorithms created for accelerometers (originally created to be placed on the waist) estimate EE by accelerations present on the mass of limbs, and during resistance training some limbs are moving while others may be inactive. As a result, accelerometers are unable to accurately detect work done in activities such as cycling, static work, isolated limb motion or to distinguish between graded and level walking. ${ }^{26}$ This may help to explain why the underestimation of EE is larger and progresses as the intensity of the exercise increases, as well as these effects could be produced by the placement of the accelerometer (e.g., ankle, waist and wrist). ${ }^{27}$

Recently, the results of multiple measurements at different body segments combining four triaxial accelerometers (3 ActiGraph GT3X and $1 \mathrm{ACT}$ ) showed that total waist accelerometer counts present higher correlation with EE measured by a portable metabolic system than total ankle and wrist counts. ${ }^{8}$

Additionally, the number of sensors is a very important point for the success of the devices' ability to accurately measure physiological states. Multiple sensors allow for the disambiguation of contexts that might confuse a single sensor. For example, if a person's motion is high, it might be due to exercising or to being in a moving vehicle. However, the contexts of EE, temperature, sweat, $\mathrm{HR}$ and heat flux are typically quite different for exercise and being in a car. A potential advantage of the SWA is that it utilizes physiological sensors that measure skin temperature, heat flux and galvanic skin response, resulting in a more accurate measurement of $\mathrm{EE}$ in activities with no regular rhythmic accelerations. Moreover, EE during walking may be inaccurately estimated when the locomotion is not horizontal, e.g., slope climbing and walking up and downstairs. Ohtaki et al. ${ }^{28}$ have shown an alternative method that use the information of altitude changes to determine movement with vertical displacement and the proposed method (accelerometer plus barometer) provides better estimation of physical activity compared to conventional accelerometer based calorie counters.

Recently, Stec and Rawson ${ }^{8}$ have shown the outputs of synchronizing the ACT with a HR monitor to improve the estimation of resistance exercise EE due to the linear relationship between $\mathrm{HR}$ and exercise intensity. ${ }^{29}$ However, the results showed that the addition of the average exercise $\mathrm{HR}$ had no meaningful effect on enhancing the ability to predict EE.

Different algorithm versions for SWA have been created to better assess PA, and differences have been found between these versions. ${ }^{30}$ For the current SWA, version used in this study, the algorithms accurately classify many activities automatically and user selection of an appropriate algorithm is no longer required.

\section{CONCLUSION}

Accelerometers underestimated EE compared with indirect calorimetry in three different CRT. More information is needed to improve the accuracy of ACT as an "EE measurement tool" and the accuracy of SWA at distinct exercise intensities.

\section{ACKNOWLEDGMENTS}

The PRONAF Study takes place with the financial support of the Ministerio de Ciencia e Innovación, Convocatoria de Ayudas I+D 2008, Proyectos de Investigación Fundamental No Orientada, del VI Plan de Investigación Nacional 2008-2011, (Contrac: DEP2008-06354-C04-01) and financed in part by the Coordenação de Aperfeiçoamento de Pessoal de Nivel SuperiorBrazil (CAPES) - Finance Code 001. Thanks to the support of the Dirección de Investigación de la Universidad Católica de la Santísima Concepción, Chile.

All authors declare no potential conflict of interest related to this article

AUTHORS' CONTRIBUTIONS: Each author made significant individual contributions to this manuscript. ABP, EAC and PJB: performed the statistical analysis and drafted the manuscript; AGZ: participated in its design and coordination and drafted the manuscript; ABP and PJB: conceived the study. All authors have read and approved the final version of the manuscript and agree with the authors' order of presentation.

\section{REFERENCES}

1. Warburton DE, Nicol CW, Bredin SS. Health benefits of physical activity: the evidence. CMAJ. 2006;174(6):801-9.

2. Drenowatz C, Eisenmann JC. Validation of the sensewear armband at high intensity exercise. Eur J Appl Physiol. 2011;111(5):883-7.

3. Lamonte MJ, Ainsworth BE. Quantifying energy expenditure and physical activity in the context of dose response. Med Sci Sports Exerc. 2001;33(6 Suppl):S370-8; discussion S419-20.

4. Levine JA. Measurement of energy expenditure. Public Health Nutr. Oct 2005;8(7A):1123-32.

5. Volp AC, Oliveira FC, Alves RD, Esteves EA, Bressan J. Energy expenditure: components and evaluation methods. Nutr Hosp. 2011;26(3):430-40.

6. Chen KY, Bassett Jr DR. The technology of accelerometry-based activity monitors: current and future. Med Sci Sports Exerc. 2005;37(11 Suppl):S490-500.

7. King GA, Torres N, Potter C, Brooks TJ, Coleman KJ. Comparison of activity monitors to estimate energy cost of treadmill exercise. Med Sci Sports Exerc. 2004;36(7):1244-51.
8. Stec MJ, Rawson ES. Estimation of resistance exercise energy expenditure using triaxial accelerometry. J Strength Cond Res. 2012;26(5):1413-22.

9. Benito PJ, Neiva C, Gonzalez-Quijano PS, Cupeiro R, Morencos E, Peinado AB. Validation of the SenseWear armband in circuit resistance training with different loads. Eur J Appl Physiol. 2012;112(8):3155-9.

10. Scott CB, Kemp RB. Direct and indirect calorimetry of lactate oxidation: implications for whole-body energy expenditure. J Sports Sci. 2005;23(1):15-9.

11. Díaz V, Benito PJ, Peinado AB, Alvarez M, Martín C, Di Salvo V, et al. Validation of a new portable metabolic system during an incremental running test. J Sports Sci Med. 2008;7(4):532-6.

12. Rosdahl H, Gullstrand L, Salier-Eriksson J, Johansson P, Schantz P. Evaluation of the oxycon mobile metabolic system against the Douglas bag method. Eur J Appl Physiol. 2010;109(2):159-71.

13. St-Onge M, Mignault D, Allison DB, Rabasa-Lhoret R. Evaluation of a portable device to measure daily energy expenditure in free-living adults. Am J Clin Nutr. 2007;85(3):742-9. 
14. Fruin ML, Rankin JW.Validity of a multi-sensor armband in estimating rest and exercise energy expenditure. Med Sci Sports Exerc. 2004;36(6):1063-9.

15. Rothney MP, Schaefer EV, Neumann MM, Choi L, Chen KY. Validity of physical activity intensity predictions by actigraph, actical, and RT3 accelerometers. Obesity (Silver Spring). 2008;16(8):1946-52.

16. Crouter SE, Churilla JR, Bassett Jr DR. Estimating energy expenditure using accelerometers. Eur J Appl Physiol. 2006;98(6):601-12.

17. Crouter SE, Clowers KG, Bassett Jr DR. A novel method for using accelerometer data to predict energy expenditure. J Appl Physiol (1985). 2006;100(4):1324-31.

18. Freedson PS, Melanson E, Sirard J. Calibration of the Computer Science and Applications, Inc. accelerometer. Med Sci Sports Exerc. 1998;30(5):777-81

19. Karvonen J, Vuorimaa T. Heart rate and exercise intensity during sports activities. Practical application. Sports Med. 1988;5(5):303-11.

20. Bammann K, Sioen I, Huybrechts I, Casajús JA, Vicente-Rodríguez G, Cuthill R, et al. The IDEFICS validation study on field methods for assessing physical activity and body composition in children: design and data collection. Int J Obes (Lond). 2011;35(Suppl 1):S79-87.

21. Neuls F.Validity and reliability of"step count"function of the actitrainer activity monitor under controlled conditions. Acta Univ Palacki Olomuc Gymn. 2008;38(2):55-64

22. Rawson ES, Walsh TM. Estimation of resistance exercise energy expenditure using accelerometry. Med Sci Sports Exerc. 2010;42(3):622-8
23. Theou O, Jakobi JM, Vandervoort AA, Jones GR. A comparison of physical activity (PA) assessment tools across levels of frailty. Arch Gerontol Geriatr. 2012;54(3):e307-14

24. van Coevering P, Harnack L, Schmitz K, Fulton JE, Galuska DA, Gao S. Feasibility of using accelerometer to measure physical activity in young adolescents. Med Sci Sports Exerc. 2005;37(5):867-71.

25. Koehler K, de Marees M, Braun H, Schaenzer W. Comparison of two portable devices for assessing energy expenditure during high-intensity running. Med Sci Sports Exerc. 2010;42(5 Suppl):S304-5.

26. Warren JM, Ekelund U, Besson H, Mezzani A, Geladas N, Vanhees L, et al. Assessment of physical activity - a review of methodologies with reference to epidemiological research: a report of the exercise physiology section of the European Association of Cardiovascular Prevention and Rehabilitation. Eur J Cardiovasc Prev Rehabil. 2010;17(2):127-39.

27. Johannsen DL, Welk GJ, Sharp RL, Flakoll PJ. Differences in daily energy expenditure in lean and obese women: the role of posture allocation. Obesity (Silver Spring). 2008;16(1):34-9.

28. Ohtaki A, Susumago M, Suzuki A, Sagawa K, Nagatomi R, Inooka H. Automatic classification of ambulatory movements and evaluation of energy consumptions utilizing accelerometers and a barometer. Microsyst Technol. 2005;8(8-11):1034-40.

29. Peinado PJ, Sánchez MA, Molina VD, Losano AB, Montero FJ. Aerobic energy expenditure and intensity prediction during a specific circuit weight training: a pilot study. J Hum Sport Exer. 2010;5(2):134-45.

30. Cole PJ, LeMura LM, Klinger TA, Strohecker K, McConnell TR. Measuring energy expenditure in cardiac patients using the Body Media Armband versus indirect calorimetry. A validation study. J Sports Med Phys Fitness. 2004;44(3):262-71. 